\title{
Compassion and the Art of Family Medicine: From Osler to Oprah
}

\author{
Robert E. Rakel, MD
}

It is an honor and a privilege to be invited to give the Pisacano lecture. Nick was a good friend and almost singularly responsible for establishing our specialty on a solid foundation of clinical competence and compassionate, comprehensive care. He was also a lover of the arts, especially music and literature. Thus, I have used "the art of family medicine" in my title to reflect on the role of the arts in our discipline, as I think Nick would have appreciated. In fact, Nick once said that "someday, when the Board is going well, I would like to help rebuild the image of the physician. I'd like to see him study Shakespeare and the Bible. Medicine is a scientific discipline based on humanism."

It has been 10 years since Nick's death on 11 March 1990, yet he is still considered the father of family practice. He was a scholarly man of dignity, distinction, and enormous courage, and he was devoted to the highest moral and ethical principles that guide the medical profession. The welfare of the patient was foremost in everything he supported.

Nick played piano to finance his way through medical school, and he remained an excellent player. He was also one of the University of Kentucky's most popular professors. For more than 20 years he taught "Introduction to Human Biology" to a standing-room-only auditorium of 200 undergraduates, and for his last 10 years he taught the course without receiving a salary.

Before the changes of the past century, the practice of medicine could be illustrated by a single picture, a physician seated at a bedside, studying a sick patient and administering the most effective available treatment: compassion. This picture is

Submitted 19 June 2000.

From the Department of Family Medicine, Baylor College of Medicine, Houston, Texas. Address reprint requests to Robert E. Rakel, MD, Department of Family and Community Medicine, Baylor College of Medicine, 5510 Greenbriar, Houston, TX 77005.
The Doctor, by Sir Luke Fildes. It shows the caring physician at the bedside of an ill child, concerned, but helpless. Fildes' masterpiece was commissioned by Henry Tate and hangs in the Tate Gallery in London. It was inspired by the memory of the death of Fildes' son in 1877 and by the professional devotion of their family physician, Dr. Gustavus Murray, who attended him. The painting is intended to show the child making the first signs of recovery as dawn breaks through the window.

Another illustration would be the photograph of Sir William Osler at the bedside contemplating, with his attendant students, the physical clues to an elusive diagnosis.

The first image portrays the frustration of a physician who has little to offer the patient and family beyond companionship, compassion, and watchful waiting. The latter image, despite the magnetism of Osler's personality and the awesome presence of his entourage, is equally ineffective. If the patient in question was suffering from pneumonia, then neither physician possessed the potent antibiotics we have today, although these miracle drugs are breeding a new generation of resistant organisms, and thus we may soon have come full circle. Indeed, the mortality from Streptococcus pneumoniae and Mycobacterium tuberculosis infections remains disturbingly high.

\section{Compassion}

If Sir William Osler were practicing today and were asked what trait of the physician he would most like to see endure into the 21 st century, I hope we would all agree that it would be compassion. Osler ${ }^{2}$ said, "It is more important to know what patient has a disease, than what disease the patient has."

Similarly, Maimonides, ${ }^{3}$ in the 12 th century, said, "May I never see in the patient anything but a fellow creature in pain. May I never consider him merely a vessel of disease." Too often today, it 
appears that concern for the patient is being replaced by preoccupation with disease.

Caring for patients and alleviation of their suffering is our highest priority. Peabody ${ }^{4}$ said, "One of the essential qualities of the clinician is interest in humanity, for the secret of the care of the patient is in caring for the patient."

In one sense, it is an indictment of the medical profession that Peabody's paper The Care of the Patient, published in 1927, has for more than a half-century been so popular and so necessary. Our preoccupation with biomedical medicine has not only diminished the attention given to the biopsychosocial, but some believe it has actually denigrated it as irrelevant. Compassion is an essential component of high-quality medical care in today's technological world of medicine.

The caring function of family medicine emphasizes our personalized approach to health care and our commitment to understanding the patient as a person, respecting the person as an individual, and showing compassion for his or her discomfort. Compassion, from the word patior, literally means "to suffer with," to share in another's distress and to be moved to give relief. Compassion reflects the physician's willingness to share the patient's anguish and to attempt to understand what the sickness means to that person.

Compassion involves both sympathy and empathy. Sympathy could be described as involving compassion but not passion. Sympathy is the sharing or understanding of the feelings of another person. Empathy, derived from the German Einfuiblung, which means "feeling into," involves a closer and more involved understanding and identification with another person.

It has been said that more mistakes in medicine are made by those who do not care than by those who do not know.

Nick, in his remarks at the 20th anniversary of the American Board of Family Practice, quoted Bill Ross, former head of family practice at the University of Texas, Southwestern in Dallas. "Why does it seem that the more we learn, the less we care. Does this mean that knowledge breeds contempt?"1

Caring implies that empathy, which is the capacity of physicians to participate in the feelings of the patient, is best accomplished if physicians place themselves in the role of the patient in an effort to understand the patient's feelings. Doing so will help the physician understand and perhaps accept why the patient chooses a therapeutic option different from the one recommended. Through empathy, physicians attempt to reconcile their own beliefs about what is best with the patient's beliefs. Without an empathetic approach, physicians risk harming patients by making decisions that are not congruent with their beliefs, values, and meaning of life as they perceive it. In addition, treating patients with tenderness and caring can relieve much of their emotional suffering and contribute more to their recovery than many of the drugs we use.

Chekhov, a physician himself, thought that medical students should spend half their time learning what it feels like to be ill. Although this method for developing empathy might be extreme, it is important that the student, before becoming immersed in the technical and cognitive aspects of medicine, be able to identify with the patient's feelings, fears, and apprehensions so that the knowledge acquired during medical school can be applied meaningfully in the context of these needs. Although the physician might be able to cure a disease only occasionally, he or she can always console the patient. An unknown author has admonished the medical profession: "To cure sometimes, to relieve often, to comfort always."

\section{Modern Technology}

The family physician is in a position to minimize the often frightening and dehumanizing experiences patients are subjected to in our modern medical system. As physicians, we must constantly strive to preserve personal dignity for patients, especially when their identities are threatened by the strange and often dispassionate hospital environment. Herb Fred, ${ }^{5}$ in his article "The Tyranny of Technology," coins the term technologic tenesmus to describe the uncontrollable urge to rely on sophisticated medical gadgetry for diagnosis.

Today we have a disease cure system, not a health care system. Too often the patient is lost or forgotten in the process of diagnosis and treatment. Our current US health care system overvalues procedures at the expense of what has come to be thought of as old-fashioned medical compassion and concern. Such a system produces physicians who believe their task is to cure rather than to care. We have come to think of the body as a machine with replaceable parts, and we have forgotten that abdominal pain can come from life as well as from the gallbladder. 
Long before the medical technology explosion, Osler, as noted earlier, cautioned us to know the patient rather than the disease. Knowing the patient is part of the art of medicine. The use of sympathy, tact, and gentleness in caring for a patient is as essential to high-quality medical care as the manipulative skill of a surgeon.

Good interpersonal skills enhanced by compassion enable the physician to dissect out the tangled mass of personal difficulties that so often form the core of functional disease or magnify the symptoms of an organic condition. We all know that a broken spirit underlies a great deal of the problems we encounter in practice.

It is ironic, in this era of rapid technological advances, a time when physicians are able to do so much to help patients medically, that patient and physician each feel increasingly rejected by the other. Technology is experienced as invasive and dehumanizing. Medicine is no longer the laying on of hands; it is a physician reading signals from a computer monitor. Medicine is no longer a physician sitting at the bedside with a sympathetic hand on the patient's arm. Instead, it is a physician speaking across an expanse of desk, laboratory results in hand, at a frightened patient in need of a human touch.

Lown ${ }^{6}$ stated it this way:

Caring without science is well-intentioned kindness, but not medicine. On the other hand, science without caring empties medicine of healing and negates the great potential of an ancient profession. The two complement and are essential to the art of doctoring.

The problem is not uncaring physicians, but an increasing reliance on technological knowledge or procedures at the expense of compassion. We must not allow technology to erect barriers to caring. The essence of the art of medicine is the compassionate and effective application of technology to the care of a particular person. We must use the best technology that science has to offer, but never in a way that neglects the important emotional and social issues which make each patient unique.

Our preoccupation with biomedical medicine has not only diminished the attention given to the biopsychosocial component, but, as some believe, it may have denigrated it as irrelevant. Compassion is an essential component of high-quality medical care in today's technological world of medicine.

\section{Trust}

In a recent survey of average citizens in the United States, more than one half believed that physicians do not care about their patients as much as they used to and that physicians are too interested in making money. Our profession is in jeopardy when patients believe that we care more about our income than their well-being. We must reestablish the image of medicine as a caring profession and convince patients that we put their welfare above our self-interest.

Cranshaw and others, ${ }^{7}$ writing in The Fournal of the American Medical Association, summarized the standards by which we are judged.

By its traditions and very nature, medicine is a special kind of human activity-one that cannot be pursued effectively without the virtues of humility, honesty, intellectual integrity, compassion, and effacement of excessive selfinterest. These traits mark physicians as members of a moral community dedicated to something other than its own self-interest.

\section{Respect}

Respect for the patient is an essential ingredient in developing trust and in being able to "care with caring." Patients must believe that we value their comments and opinions before they will trust us with information of a personal nature. As long as our attitude toward the patient embodies respect, concern, and kindness, and a sincere effort is made to understand the patient's difficulties, the patient will overlook or forgive a myriad of other problems in our relationship.

Most patient complaints against physicians can be attributed to a lack of communication. A common error is to assume that patients are not interested in knowing more about their disease. Although patients with less education ask fewer questions, it is not true that they have less desire for information. Taking time to explain a procedure thoroughly, without being asked, shows respect and concern for the patient. Answering questions about unconventional forms of treatment without ridicule or contempt does the same. Our own insecurities, too, can drive a wedge between our patients and us.

Too often physicians believe that a god-like image of omnipotence is necessary to maintain patient respect and confidence. It is usually a lack of selfconfidence, however, that causes physicians to re- 
treat behind this protective image that, in turn, limits their ability to help. Secure physicians are freer to establish close personal relationships with patients. As a result, they do not worry that their position will be threatened.

\section{Listening}

Bernard Lown ${ }^{6}$ wisely noted:

In the brief time available to take a history, the aim is to obtain, in addition to essential facts, insight into the human being. This seems easy, but listening is the most complex and difficult of all the tools in a doctor's repertory. Listening is not passive. One must be an active listener to hear an unspoken problem.

Osler ${ }^{2}$ said: "Listening, not imitation, is the sincerest form of flattery. Listening is unspoken caring." He advised the physician, "Look wise, say nothing, and grunt. Speech was given to conceal thought."

Effective communication depends much more on out ability to be a good listener than on what we say to a patient. Most physicians mistakenly believe they listen more than is actually the case.

\section{We bave two ears and one mouth and should use them in that proportion.}

$$
\text { -Epictetus }
$$

\section{Be a good listener because you never learn much from talking.}

-Will Rogers

My favorite is, "It is better to remain quiet and be thought a fool than to speak and remove all doubt."

Truly listening to a person is a form of respect. The engaged and attentive listener says to that person: "I hear you. I understand what you are telling me. I value you and your opinions." To be valued and respected are great gifts-ones that are likely to be reciprocated.

\section{Care of the Dying}

Caring for a dying patient requires special skill. The dying patient is often physically and emotionally isolated from familiar surroundings and placed in a social setting that gives very low priority to individual personality, fears, and past experiences.
It is not easy to provide compassionate care for a terminally ill patient and still maintain composure and objectivity, both of which are necessary for us to remain effective as physicians. Osler ${ }^{2}$ notes that "Our equanimity is chiefly exercised in enabling us to bear with composure the misfortunes of our neighbors."

The dying patient's greatest fear is that of suffering alone and being deserted. Patients typically fear a painful death less than the loneliness and alienation that might accompany it. As a result, the dying patient's contentment is dependent upon the ability to maintain warm relationships with loved ones. When dying patients notice that people are avoiding them, they might interpret the avoidance as a rejection stemming from their failure to get better, or they might see it as the loss of love.

During the terminal stages of a fatal illness, it is vital to the dying patient that the family physician maintain a warm and caring relationship. It is not always easy, especially when the patient is being cared for by specialists and might be removed from day-to-day care. Making the effort to telephone or to stop in for a few minutes sends a powerful message. It says "someone cares, and you have not been forgotten." Often simply being willing to listen is one of the most comforting measures a physician can take in caring for dying patients and their families. We need to allow each person to talk about his or her fears, frustrations, hopes, needs, and desires. Being able to talk about problems can be very therapeutic.

If physicians and others withdraw from interaction, much of the motivation for living disappears and is replaced by despair or terminal depression. Elisabeth Kübler-Ross ${ }^{8}$ relates the following, a plea to fellow health professionals from a young student nurse who is terminally ill:

I know you feel insecure, don't know what to say, don't know what to do. But please believe me, if you care, you can't go wrong. Just admit that you are.... All I want to know is that there will be someone to hold my hand when I need it. I am afraid. Death may get to be a routine to you, but it is new to me. You may not see me as unique! ... If only we could be honest, both admit our fears, touch one another. If you really care, would you lose so much of your valuable professionalism if you even cried with me? Just person to person? 
Then, it might not be so hard to die-in a hospital-with friends close by.

Anatole Broyard, ${ }^{9}$ shortly before his death from prostate cancer, said:

I wouldn't demand a lot of my doctor's time. I just wish he would brood on my situation for perhaps five minutes, that he would give me his whole mind just once, be bonded with me for a brief space, survey my soul as well as my flesh to get at my illness, for each man is ill in his own way.... Just as he orders blood tests and bone scans of my body, I'd like my doctor to scan me, to grope for my spirit as well as my prostate. Without some such recognition, I am nothing but my illness.

On a more positive note, Joan Baez says: "You don't get to choose how you are going to die. Or when. You can only decide how you're going to live."

\section{Humor}

Our effectiveness as physicians can be enhanced by a keen sense of humor. A grin can be our most effective weapon for breaking down resistance or apprehension of patients, especially children or young adults. A genuine smile can quickly establish a friendly atmosphere.

A gentle self-deprecating sense of humor makes you more human. It is not necessarily the capacity to be funny. Humor stems from the same word as humility.

Humor, when appropriately applied to the physician-patient relationship can, in an instant, put both parties at ease in a way that usual conversation cannot. It is a nonthreatening way of reaching out to another person. How often have we stood in line next to a stranger when suddenly a humorous remark about our common situation "breaks the ice" and develops an immediate bond. Humor is the ultimate ice-breaker. ${ }^{10}$

Humor reduces the emotional distance between people. It improves communication, fosters a sense of trust, and relieves tension and anxiety. One patient said she considered a sense of humor so important in a physician that it should be a requirement for entrance into medical school.

Thomas Sydenham commented that "The arrival of a clown has a greater beneficial influence on the health of a town than twenty asses laden with drugs." 7

Francis Rabelais (1495-1553), physician and scholar, believed that to provoke laughter is to encourage health. We all know how a good belly laugh makes us feel good. Norman Cousins, ${ }^{11}$ in his Anatomy of an Illness, believed that laughter was successful in treating his ankylosing spondylitis.

When Winston Churchill became overwhelmed with paperwork, often to the neglect of guests, his secretary would remind him of rule 6 , which was "Never take yourself too seriously." When a visitor asked Churchill what the other five rules were, he answered, "There are no other rules."

There are times, however, when humor is inappropriate. It can be counterproductive or even destructive if used at the wrong time or with patients who do not appreciate it. Be watchful for the right moment to introduce humor. Inappropriate joviality at the wrong time can offend a patient who considers the illness a serious matter not to be taken lightly. Hippocrates is said to have written: "In appearance, let the physician be of a serious but not a harsh countenance; for harshness is taken to mean arrogance and unkindness, while a man of uncontrolled laughter and excessive gaiety is considered vulgar, and vulgarity especially must be avoided." 12

\section{Compassion and the Art of Medicine}

The humanities can play an important role in maintaining empathy and in cultivating the compassion that students have on entry into medical school. At Baylor College of Medicine, our department sponsors a series of lectures by physicians, artists, and patients on the subject of "compassion and the art of medicine." The purpose is to encourage medical students and health care professionals to become more compassionate and more effective health care providers by applying the principles of medical humanism to everyday clinical practice.

We invite speakers who are able to articulate their experiences of illness and suffering. Too often, students are exposed to patients who function as specimens under glass, and they seldom have the opportunity to spend an hour listening to patients reflect on the meaning of their illness and the quality of care they have received. Speakers include patients who describe examples of compassion or the lack thereof during an illness. 
One example is Sue Baier, ${ }^{13}$ who wrote of her experiences with Guillain-Barré syndrome in Bed Number Ten. Baier describes the experience of being ignored as a person (nurses and physicians would talk to each other as though she were not present) and of being "handled" as an inanimate object because she was unable to move any muscles except to blink. She was fully alert, however. Because she was paralyzed, attendants did not realize that her sensory system was fully intact and that she experienced considerable discomfort from a rough venipuncture or from lying on a wrinkled bed sheet.

Another speaker, author and surgeon Richard Selzer, ${ }^{14}$ in his book Raising the Dead, describes his Legionnaires' disease, involving 23 days of coma and then death. The amazing part of the story (if it can be believed) is that 10 minutes after being pronounced dead (which occurred after his electroencephalogram was flat for 5 minutes), he recovered. A brain deprived of adequate oxygen that long usually suffers permanent damage, yet his account shows his writing skills are as sharp as before the illness.

The other focus of our series is the art of medicine. In an effort to help students hone their "people skills," we invite writers, artists, and performing artists to read to us from their writings, to present slides of their visual art, or to give dramatic performances on various clinical themes. Some are physicians and others draw from their experiences as patients, many describing problems that make physicians uncomfortable, such as drug dependency, alcoholism, and near death. Originally, we focused on nationally prominent speakers to articulate these themes. Our experience has shown, however, that the responsiveness of students is usually determined more by the genuineness of the speakers than by their prominence. Speakers who draw from their own illness or experience are the ones who have the greatest impact and potential to educate and motivate our students.

\section{The Secret of Success-Persistent Curiosity}

How do we, as physicians, remain perpetually stimulated and excited by medicine when the continuous weight of overbearing responsibility tends to wear us down and burn us out? One essential ingredient for a successful career in medicine is a persistent curiosity and enthusiasm for learning. Curiosity is an appetite for knowledge and is the basis for new discoveries in medicine.

Leonardo da Vinci applied his voracious curiosity and superb artistry to the study of the world around him: "Just as iron rusts from disuse, even so does inaction spoil the intellect."

Cato the Elder (who learned Greek at age 80 years) said, when he was 84 years old, "Old men retain their intellects well enough, if only they keep their minds active and fully employed."

In popular jargon, this means to "use it or lose it." Students at Baylor confirm that elderly persons who continue to "exercise their minds" maintain memory function to a greater extent than those who do not. When Oliver Wendell Holmes was in his 80 s, someone found him reading Plato and wondered why. "To improve my mind," Holmes replied.

It was a persistent curiosity that prompted most of the general practitioner-investigators of the past to achieve greatness: Robert Koch, the father of bacteriology; William Pickles, the father of epidemiology; James McKenzie, the father of cardiology; William Beaumont, the father of gastroenterology; and William Jenner, whose studies led to the firstever eradication of a disease from this earth, are only a few.

Those of us in academic medicine are the adult version of the perpetual student. My favorite publication of Sir William Osler ${ }^{2}$ is $A$ Way of Life, a lecture given to Yale medical students on 20 April 1913. Osler begins by addressing his readers as fellow students. Clearly, Osler believed that we should never lose our thirst for knowledge and that inquisitiveness and curiosity are essential to continued improvement as a physician.

Osler emphasizes the importance of students cultivating the ability to focus on a task and concentrate on it completely for 3 to 4 hours each day.

Realize how much time there is, (and) how long the day is. You have sixteen waking hours, three or four of which at least should be devoted to making a silent conquest of your mental machinery ... the failure to cultivate the power of peaceful concentration is the greatest single cause of mental breakdown ... a few hours out of the sixteen will suffice, only let them be hours of daily dedication. 
Osler's theme is based on a maxim of Carlyle, to which he credits much of his success. "Our main business is not to see what lies dimly at a distance, but to do what lies clearly at hand."

After the address was printed, Osler asked that future printings include the poem from the Sanskrit that embodies this philosophy, Listen to the Exbortation of the Dawn, which has become a favorite of mine and I am sure of many other Oslerians.

\section{Listen to the Exhortation of the Dawn! \\ Look to this Day! \\ For it is Life, the very Life of Life. \\ In its brief Course lie all the \\ Varieties and Realities of your Existence: \\ The Bliss of Growth, \\ The Glory of Action, \\ The Splendour of Beauty; \\ For Yesterday is but a Dream \\ And Tomorrow is only a Vision; \\ But Today well lived makes \\ Every Yesterday a Dream of Happiness, \\ And every Tomorrow a Vision of Hope. \\ Look well therefore to this Day! \\ Such is the Salutation of the Dawn!}

What Osler proposes is that once the activity for the day has been decided upon, give it a concentrated, uninterrupted block of time. All serious writers know this to be necessary.

\section{Reading}

You do not need to burn books to destroy a culture. Just get people to stop reading them.

\section{If your doctor knows only medicine, you can be sure that he knows not even medicine.} -Mark Twain

Osler recommended that to be well-rounded, physicians should read a nonmedical classic for a half-hour each day, before retiring for example. He advises, "Let no day pass without contact with the best literature of the world... . Fifteen or twenty minutes day by day will give you fellowship with the great minds of the race, and little by little as the years pass you extend your friendship with the immortal dead." His list of recommended books reflects the religious and classical atmosphere in which he was reared and is clearly a 19th century view of the classical world. I surveyed members of

\begin{tabular}{ll}
\hline 1904 & \multicolumn{1}{c}{1985} \\
\hline $\begin{array}{l}\text { 1. Old and New } \\
\text { Testament }\end{array}$ & 1. Sir William Osler \\
2. Shakespeare & 2. Harvey Cushing \\
3. Montaigne & 3. Old and New Testament \\
4. Plutarch's Lives & 4. Shakespeare \\
5. Marcus Aurelius & 5. Arthur Conan Doyle \\
6. Epictetus & 6. Lewis Thomas \\
7. Religio Medici & 7. Cervantes (Don Quixote) \\
8. Don Quixote & 8. Oliver Wendell Holmes \\
9. Emerson & 9. James Michener \\
10. Oliver Wendell Holmes & 10. Churchill and Dickens (tie) \\
\hline
\end{tabular}

the American Osler Society in an attempt to revise Osler's list to make it more modern and meaningful for today's medical students.

Each of us should calculate how many books we normally read in a year and how many years of life we probably have remaining. Simple arithmetic will tell us how many books we can read in the time remaining. Because the list of books each of us would like to read is longer than the time we have, we should follow Sir William's advice and concentrate on those that are most important to us and the most rewarding.

\section{Time-To Care for Our Patients and for Ourselves}

To care with caring is not an easy task. Societal and economic forces combine to discourage the level of comprehensive care we all would like to provide. Time and money are the enemies. In the United States and elsewhere, physicians are pressured to be efficient, cost-effective providers-and caring takes time.

Bulger" ${ }^{15}$ notes, "With health care time inordinately rationed today in the interest of economy, Americans could organize themselves right out of compassion." He describes the Good Samaritan experiment ${ }^{16}$ where seminary students who, while rushing to an appointment, encountered a man writhing on the ground in pain. Those under the greatest time pressure were least likely to stop and help, even though they were on their way to give a talk on the parable of the Good Samaritan. Rationing time might reduce costs, but it can also compromise quality, which could prove disastrous to all of medicine. ${ }^{16}$ 
American industry learned a long time ago that you can make only so much progress by flogging the horse harder. You must replace the horse with a truck and focus on quality, outcome, and patient satisfaction. Seeing more patients in less time is not the answer.

Modern medicine is dramatically different than it was 50 years ago. There are now more than 2,000 medical journals in the English language alone.

Clearly it is easier-and seemingly more costeffective-to write a prescription than to sit down and listen to the newly widowed patient talk about her grief. Treating that patient's complaint is to provide care; taking time to really listen to her is caring. We know which approach is the more compassionate one. The question is, how do we do it?

That is the challenge facing all of us as family physicians-to find a way to always be compassionate, to develop empathy, to build trust, to show respect, and to truly listen to our patients. The obstacles are many, but the rewards are great, not only for those who entrust us with their care but for ourselves as well.

When choosing a career, the trick is to find a job that you would do for free if life afforded you that opportunity.

-Unknown author

If you want others to be happy, practice compassion. If you want to be bappy, practice compassion.

-Dalai Lama ${ }^{17}$

How do we maintain our energy and enthusiasm in the midst of patient demands and the time constraints of practice? One solution is to enjoy the journey and not always focus on the destination. How much would you really care about that next promotion, bigger paycheck, or larger house if you blew an aneurysm one afternoon or found a lump in your breast?

Oprah Winfrey ${ }^{18}$ has said, "Part of the reason why I am as successful as I have been is because

* From A Penny's Wortb of Minced Ham by Robert J. Hastings. (C) 1986 by The Board of Trustees, Southern Illinois University, reprinted by permission. success wasn't the goal. The process was. I wanted to do good work." She also advised students,

"Don't tell me you want to do great things with your life if all you carry to school is a radio."

The Station ${ }^{\star}$ by Robert Hastings ${ }^{19}$ puts it in perspective:

Tucked away in our subconscious is an idyllic vision. We see ourselves on a long trip that spans the continent. We are traveling by train. Out the windows we drink in the passing scene of cars on nearby highways, of children waving at a crossing, of cattle grazing on a distant hillside, of smoke pouring from a power plant, of row upon row of corn and wheat, of flatlands and valleys, of mountains and rolling hillsides, of city skylines and village halls.

But uppermost in our minds is the final destination. On a certain day at a certain hour, we will pull into the station. Bands will be playing and flags waving. Once we get there, so many wonderful dreams will come true and the pieces of our lives will fit together like a completed jigsaw puzzle. How restlessly we pace the aisles, damning the minutes for loiteringwaiting, waiting, waiting for the station.

"When we reach the station, that will be it!," we cry. "When I'm 18." "When I buy a new 450SL Mercedes Benz!" "When I put the last kid through college." "When I have paid off the mortgage!" "When I get a promotion." "When I reach the age of retirement, I shall live happily ever after!"

Sooner or later we must realize there is no station, no place to arrive at once and for all. The true joy of life is the trip. The station is only a dream. It constantly outdistances us.

"Relish the moment" is a good motto, especially when coupled with Psalm 118:24: "This is the day which the Lord hath made: we will rejoice and be glad in it." It isn't the burdens of today that drive men mad. It is the regrets over yesterday and the fear of tomorrow. Regret and fear are twin thieves who rob us of today.

So stop pacing the aisles and counting the miles. Instead, climb more mountains, eat more ice cream, go barefoot more often, swim more rivers, watch more sunsets, laugh more, cry less. Life must be lived as we go along. The station will come soon enough. 


\section{References}

1. Pisacano NJ: Introductory remarks. Medical education: time for a change. J Am Board Fam Pract 1990;3(Suppl): 3-5.

2. Osler W. A way of life. An address delivered to Yale students on the evening, April 20th, 1913. Springfield, Ill: C C Thomas, 1919.

3. Maimonides; Friedenwald $\mathrm{H}$, trans. Oath and prayer of Maimonides. Bull Johns Hopkins Hosp 1917;28: 260-1.

4. Peabody FW. The care of the patient. JAMA 1927; 88:877-82.

5. Fred HL: The tyranny of technology. Hosp Pract (Off Ed) 1997;32(3):17-8, 21.

6. Lown B. Lost art of healing. New York: Houghton Mifflin, 1996.

7. Cranshaw R, Rogers DE, Pellegrino ED, et al. Patient-physician covenant. JAMA 1995; 273:1553.

8. Kübler-Ross, E. Death: the final stage of growth. Englewood Cliffs, NJ: Prentice-Hall, 1975:26.

9. Broyard A. Intoxicated by my illness. New York: Random House Value Publishing, 1994.

10. Rakel RE: Humor and humanism. Houston Med 1989;5:7-9.

11. Cousins, N, Dubos-Rene J. Anatomy of an illness as perceived by the patient: reflections on healing and regeneration. New York: W W Norton, 1979.

12. Kibre P. Hippocrates latinus: repertorium of Hippocratic writings in the Latin middle ages. Bronx, NY: Fordham University Press, 1985.

13. Baier S, Zimmeth M. Bed number ten. New York: Holt, Reinhart \& Winston, 1986.

14. Selzer R. Raising the dead: a doctor's encounter with his own mortality. New York: Viking-Penguin, 1994.

15. Bulger RJ: The quest for mercy: The forgotten ingredient in health care reform. Charlottesville, Va: Carden Jennings Publishing, 1997.

16. Darley JM, Batson D. From Jerusalem to Jericho: a study of situational and dispositional variables in helping behavior. J Pers Soc Psychol 1973;27:100-8.

17. HH Dalai Lama, Cutler HC. The art of happiness: a handbook for living. New York: Riverhead Books, 1998.

18. Lowe JC. Oprah Winfrey speaks: insights from the world's most influential voice. New York: John Wiley \& Sons, 1998.

19. Hastings RJ. The station. In: A penny's worth of minced ham: another look at the great depression. Carbondale, Ill: Southern Illinois University Press, 1986;90-1. 